\title{
Effect of high temperature on growth performance of calves maintained in outdoor hutches
}

\author{
J. Broucek ${ }^{1}$, P. Kisac, M. Uhrincat, A. Hanus and F. Benc \\ Research Institute of Animal Production, Slovak Agricultural Research Centre \\ Hlohovska 2, 949092, Nitra, Slovakia
}

(Received 7 February 2008; accepted 8 April 2008)

\begin{abstract}
The aim of this work was to evaluate effects of high temperature on the growth, feed intake and health condition of calves kept in individual hutches in southern Slovakia. We tested a hypothesis that the calf performance would be influenced by the season at birth, sire lineage and gender. Sixtythree Holstein calves were reared in individual hutches from the second day of life to weaning at the age of 8 weeks. The calves originated from 5 sires. All calves were divided according to the temperature period at birth. The effects of period were determined according to two patterns: in pattern A, a low temperature period 1 (LT1, from April 4 to June 11, 69 days), high temperature period (HT, from June 12 to September 14, 95 days) and low temperature period 2 (from September 15 to November 24, 70 days) were distinguished; in pattern B, the results obtained in the LT1 and LT2 periods were combined and compared with those found in HT period. The same conditions of nutrition were ensured. We recorded 62 summer days and 14 tropical days during HT. Sixty-six days with the THI value above 72.0 and twenty-six with the values higher than 78.0 were found. The calves born during the HT had the lowest body weight from the first week to the weaning in the both patterns $(\mathrm{P}<0.05)$. These calves drank up the most of water to the weaning, and had the least intake of starter mixture $(\mathrm{P}<0.05)$.
\end{abstract}

KEY WORDS: dairy calf, temperatures, growth, feed intake, health, housing

\section{INTRODUCTION}

The calves kept in hutches are affected by the complex relationships among external environment, housing microclimate, and their thermal status. Hutches have been used successfully for calf rearing. However, given the potential

\footnotetext{
${ }^{1}$ Corresponding author: e-mail: broucek@scpv.sk
} 
problems of high temperature effect, calves housed outside can be exposed to significant heat stress during summer (Broucek et al., 1990; Maltz et al., 2000). The calves maintained in hutches and exposed to direct sunlight would receive an additional radiant heat load than those maintained in the shaded environment. Long-term exposure of calves to heat stress can produce adaptive changes in body function, such as continuous reduction in rectal temperature and respiration rate (Spain and Spiers, 1996).

Solar radiation and low humidity could be identified as major factors contributing to the heat stress of pre-weaned calves. In order to maintain body temperature within the normal range, calves must exchange heat with the environment (Soch et al., 1999). It can explain why calves reared in hutches during summer consume less concentrate feed and have lower average daily gains than control calves, kept in insulated and ventilated calf barn (Coleman et al., 1996).

Heat stress results from the combined effects of relative humidity and ambient temperature. Therefore, the temperature humidity index (THI) is commonly used to indicate the degree of stress on dairy cattle. THI values suggest that within the normal range up to 70, cattle show optimal performance. Dairy cattle are beginning to be stressed when the THI exceeds 72 (Davis et al., 2003). Critical THI values are over 78 .

The aim of this study was find effects of temperatures on the growth, water intake and feed consumption of calves kept in individual outdoor hutches in southern Slovakia. We tested a hypothesis that the calf performance would be influenced by the season at birth, sire lineage and gender.

\section{MATERIAL AND METHODS}

\section{Experimental design, housing and feeding of calves}

Sixty-three (30 females and 33 males) Holstein calves were used. The calves were divided into three groups according to the period of birth: low temperature period 1 (LT1, from April 4 to June 11, 69 days, $n=18,12$ males and 6 females), high temperature period (HT, from June 12 to September 14, 95 days, $n=30,15$ males and 15 females), and low temperature period 2 (LT2, from September 15 to November 24, 70 days, $\mathrm{n}=15,6$ males and 9 females). The results were evaluated either by comparison of all three groups (pattern A) or by comparison of group HT vs LT (combined values for LT1 and LT2 groups) (pattern B). The calves originated from 5 sires $(\mathrm{S} 1, \mathrm{n}=11 ; \mathrm{S} 2, \mathrm{n}=13 ; \mathrm{S} 3, \mathrm{n}=7 ; \mathrm{S} 4, \mathrm{n}=20 ; \mathrm{S} 5, \mathrm{n}=12)$.

The calves were reared in fibre-glass laminated calf hutches (white colour) from the second day of life to weaning at the age of 8 weeks. Each hutch $(1.8 \times 1.2$ $\mathrm{m}$ ) had an outside fenced yard of $1.8 \times 1.2 \mathrm{~m}$ and was bedded with straw. Hutches 
were arranged in rows, $0.8 \mathrm{~m}$ apart, oriented east to west to minimize exposure to solar heating. Hutches remained in the same location for the duration of the study. Cold drafts from blowing winter winds were blocked by the wall.

Calves received colostrum and mothers milk ad libitum three times a day from a bucket with nipple from the second to fourth day. From the fifth day they received $6 \mathrm{~kg}$ of milk replacer per day divided into 2 portions in $12 \mathrm{~h}$ intervals. From the second day until weaning the calves were offered concentrate mixture and lucerne hay ad libitum. Feed and water refusals were removed and weighed each morning prior to feeding.

Air temperature and relative humidity were recorded by measuring equipment during the entire $24 \mathrm{~h}$ periods. The equipment was placed in the centre of the calf hutches area at the same height as the withers of a standing calf.

Temperature-humidity index was calculated as proposed by Nienaber et al. (1999) by combining maximum temperature (in ${ }^{\circ} \mathrm{C}$ ) and average relative humidity (\%) per day with the following equation:

$$
\mathrm{THI}=(0.8 \times \mathrm{Tmax})+(\% \text { average } \mathrm{RH} / 100) \times(\operatorname{Tmax}-14.4)+46.4 .
$$

Colour and consistency of faeces and health condition was evaluated two times daily according to Larson et al. (1977).

\section{Statistical analysis}

The data were analysed using a General Linear Model ANOVA (three ways with the interactions) by the statistical package STATISTICS, Version 8.0 (Anonymous, 2001). The normal distribution of data was evaluated by WilkShapiro/Rankin Plot procedure. Significant differences among means were tested by Bonferroni's test.

\section{RESULTS}

During HT period 62 summer days and 14 tropical days were recorded. Sixty-six days with the value above $72.0 \mathrm{THI}$, which is already a stressor, were found during the period. The total number of days with the values higher than $78.0 \mathrm{THI}$, which was a substantial stress, was twenty-six for the whole HT period.

The calves born during the HT period had the lowest live body weight from the first week to the weaning in the both patterns. The highest growth was recorded in calves born in the LT2 period. The differences among groups were statistically significant only in the pattern B, from the 5 th to the 8 th weeks (LT $56.27 \mathrm{~kg}$ vs HT $52.56 \mathrm{~kg}$; LT $59.84 \mathrm{~kg}$ vs HT $55.61 \mathrm{~kg}$; LT 64.18 vs HT $59.60 \mathrm{~kg}$; LT $69.15 \mathrm{~kg}$ vs HT $64.51 \mathrm{~kg} ; \mathrm{P}<0.05)$. 


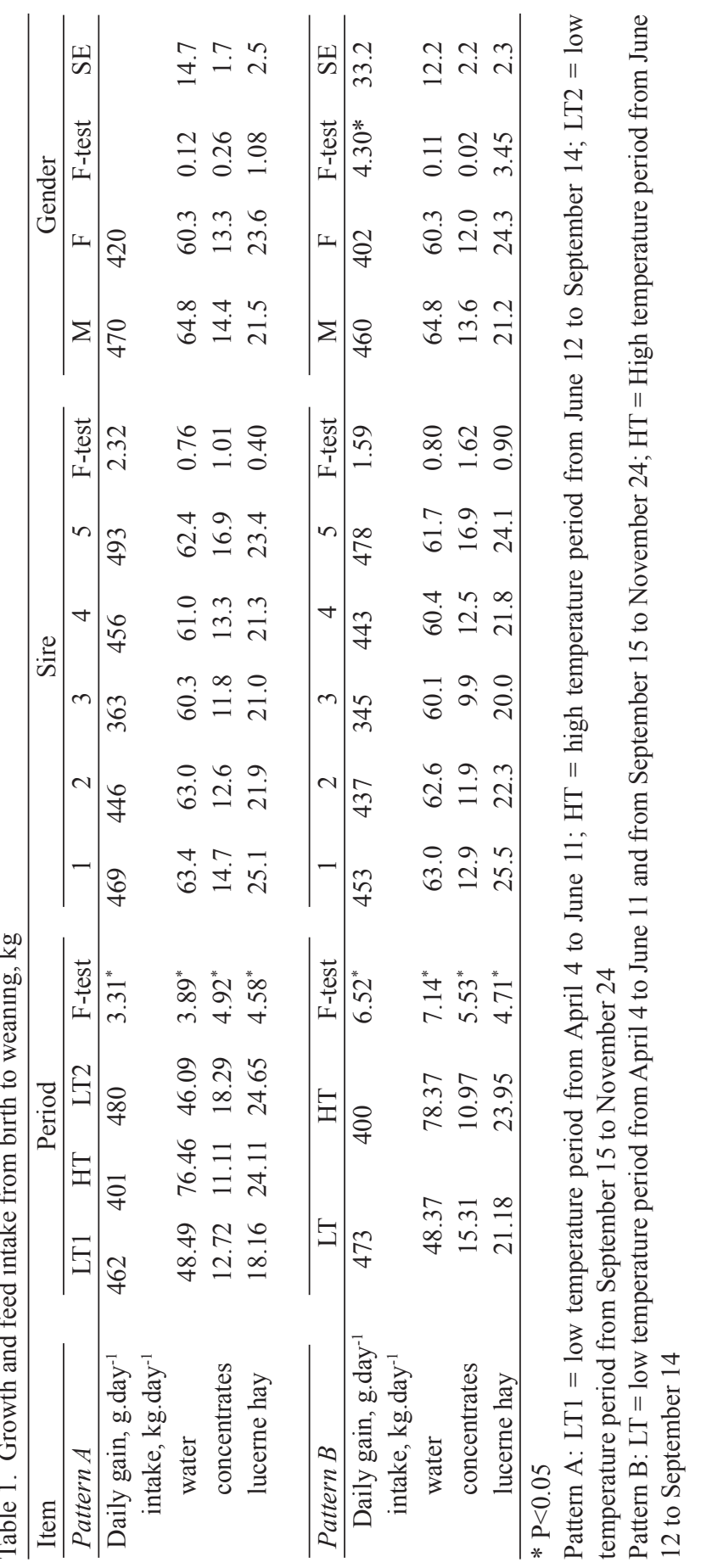


Significant difference of the average daily gains was found in the pattern A in the first week and for period from the birth to weaning (Table 1). More significant differences were found in the pattern B - weeks 1, 2, 5 and for whole experiment. Daily gains were higher in LT group in all cases. Differences were also among sire lines in the second week. The most intensive growth was recorded in males, especially for whole milk drinking period in the pattern $\mathrm{B}(\mathrm{P}<0.05)$.

Calves born in the HT period drank the greatest amount of water during the whole experiment in the both patterns $(\mathrm{P}<0.05$; Table 1$)$. We found significant differences among groups in weeks 2, 3, 4, 5 and 6 in the both patterns and also among sire lineages in the second and third week.

The highest intake of concentrates mixture was found in the group LT2 in the all milk drinking period $(\mathrm{P}<0.05$; Table 1$)$. The greatest differences were obtained between groups of this pattern $\mathrm{A}$ from the third to fifth weeks $(\mathrm{P}<0.001)$ and then in the first and sixth weeks $(\mathrm{P}<0.05)$. Similarly, starter consumption to weaning differed also in the pattern $\mathrm{B}$. The calves of group HT had the least intake and calves of group LT the most $(\mathrm{P}<0.05)$. Significant interactions period $\times \operatorname{sex}(\mathrm{P}<0.05)$ were found only in the second and third weeks.

Calves born in the LT1 period had the least lucerne hay intake to weaning in the 56 th day and calves born in the LT2 the greatest $(\mathrm{P}<0.05)$, only minor difference was found between LT2 and HT (Table 1). However, the highest consumption of hay was in the group HT in the seventh and eight weeks $(\mathrm{P}<0.05)$. It could be primarily caused by the increased intake of water. Because feeds were the same throughout the experiment, the effects associated with this phenomenon are not based on forage quality. In the pattern B we recorded similar tendency. Differences between LT and HT in the seventh week and for the whole experiment differed significantly and in the eight week highly significantly (Table 1). Lucerne hay intake was affected by the factor sire lineage in the second week in both patterns. Significant difference was recorded due to gender in the 6th week in pattern B.

Neither calf died or was culled for bad health. The faeces had liquid consistency during the first weeks, then normal firm. In the first week colour was yellow, later on green.

\section{DISCUSSION}

The main advantage of the hutch rearing of calves is the minimized risk of disease transfer from calf to calf. However, in the United States, where rearing in hutches is widespread, the temperature stress is generally disregarded (Coleman et al., 1996; Spain and Spiers, 1996). Also in scientific sources dealing with high temperature, almost all of the papers focus on dairy cows or feed-lot cattle. Our research has confirmed the findings of many authors that high air temperature can pose stress also in calves or heifers (Mader and Davis, 2004). 
In our geographical conditions we do not observe such high temperatures as in southern States of the United States, but we did record temperature above the threshold of thermoneutrality. Values of THI, as indicator of heat stress, were higher than 72 and even higher than 78, which are recognized as a significant hyperthermic stress (Davis et al., 2003).

The evaporation is intensified with an increase of the temperature of the environment. Loss of heat by utilization of the latent heat of vaporization of water is an important component of the spectrum of physiological strategies available to species that control their body temperature in the face of variable thermal loads (Robertshaw, 2006). According to Mitlöhner et al. (2002) heat stressed cattle could increase water and feed intake, stand rather than lie down, increase respiration rate and body temperature. However, calves in hutches apparently do not have other possibilities of defense. They cannot lose heat by convection or conduction, as that is possible only when air temperatures are lower than the temperature of their skin. They cannot seek out shade. Increased water consumption is typical in cattle afflicted by the hyperthermic stress. Drinking cold water decreases the temperature of blood passing through the hypothalamus, and this has an effect on thermostatic mechanisms that control feed consumption (West, 2003).

We found that calves born between June 11 and September 14 had the lowest growth intensity until weaning. These calves received the least amount of starter feed. This was consequently manifested in their growth. Effects of heat stress on performance are mainly a result of a decrease in daily feed intake, which seems to occur when ambient temperatures exceed $25^{\circ} \mathrm{C}$. Thermal heat can substantially lessen the animal's appetite, leading to decreased feed intake (Mitlöhner et al., 2002).

The results of Coleman et al. (1996) and Spain and Spiers (1996) studies show that the use of shade over calf hutches decreases the rise in hutch temperature, especially during the afternoon periods of the daily cycle, and, in turn, alleviates experienced heat stress and improves thermal status of the calf during summer. A coping strategy of cattle during heat stress is to decrease metabolic heat production by lowering feed intake, which adversely affects productivity.

Although numerous studies have reported the effectiveness of various types of housing and feeding for young dairy calves, almost all reports address the needs of reared calves (Strzetelski et al., 2001; Niwińska and Strzetelski, 2004). Rearing calves in individual outdoor calf hutches has been promoted throughout the East Central Europe since the early 1980s (Broucek et al., 1990; Soch, 2005), primarily because individual outdoor housing reduced transmission of diseases among young calves. Since the development of fibre-glass laminated hutches that retain solar radiation, the popularity of calf hutches has increased. However, the accumulation of solar heat by plastic hutches could be a distinct disadvantage.

There are some general approaches to cooling dairy calves. One must either modify the environment to prevent heat stress or implement methods that increase 
heat dissipation from the skin of cattle. Air conditioning is the ultimate method to modify a warm environment. It reduces air temperature and relative humidity lowering the THI of the environment below thermally stressful levels. However, this is not an economical choice for improving the environment of dairy calves. A more effective method to reduce air temperature is by evaporative cooling. As recommended Coleman et al. (1996) and Spain and Spears (1996), the most practical methods to reduce heat stress in calves can be housing in the shade with good ventilation. When not enough natural shade is available, artificial shades can provide needed shelter from the effects of solar radiation.

It is generally accepted that cattle begin to experience heat stress when the temperature humidity index (THI) exceeds 72 . Heat stressed animals are seeking out shade, which they often will not leave to drink or eat, increasing water intake and reducing feed intake, standing rather than lie down, increasing respiration rate, body temperature, and saliva production (West, 2003). Heat stress can result in sick animals which require prolonged care. However, no significant differences in the health and parameters of faeces were found in our study.

High temperature have not only a direct effect on growth of calves, but also a latent effect during a dry period of their mothers, especially in the last $60 \mathrm{~d}$ of gestation on milk performance of dairy cows (Broucek et al., 2005, 2007). This may lead to a decreased immunity and transfer of maternal immunoglobulins to colostrum, vigour and ability of the newborn calf to absorb immunoglobulins during hot weather.

\section{CONCLUSIONS}

Results of this study indicate that hyperthermic stress is a negative factor of calves' environment. Heat stress affects performance mainly as a result of a deteriorating animal's appetite and decreased feed intake.

We can conclude that in the East Central Europe heat stress negatively affects calves maintained in hutch. Rearing calves in this outdoor housing reduced transmission of diseases among young calves. However, it is absolutely necessary that calves have adequate comfort and are protected by a screen that isolates them from direct sun and the high temperature. Hutches used for calves during summer should be provided with supplemental shade to reduce heat stress.

Calf needs to increase water intake during times of heat stress to dissipate heat through the lungs and by sweating. Environmental modifications such as water applications can be used to provide the animals with means of cooling. 


\section{REFERENCES}

Anonymous, 2001. Statistics for Windows. Version 8.0. User`s Manual. Analytical Software. Tallahassee, FL (USA), pp. 333

Broucek J., Kovalcik K., Letkovicova M., Novak L., 1990. Evaluation of ethological parameters in calves kept in outdoor hutches. Czech J. Anim. Sci. 35, 301-310

Broucek J., Mihina S., Kisac P., Hanus A., Uhrincat M., Foltys V., Benc F., 2005. Environmental factors and progeny affecting milk yield and composition during the first lactation. J. Anim. Feed Sci. $14,461-481$

Broucek J., Ryba S., Mihina S., Uhrincat M., Kisac P., 2007. Impact of thermal-humidity index on milk yield under conditions of different dairy management. J. Anim. Feed Sci. 16, 329-345

Coleman D.A., Moss B.R., McCaskey T.A., 1996. Supplemental shade for dairy calves reared in commercial calf hutches in a southern climate. J. Dairy Sci. 79, 2038-2043

Davis M.S., Mader T.L., Holt S.M., Parkhurst A.M., 2003. Strategies to reduce feedlot cattle heat stress: Effects on tympanic temperature. J. Anim. Sci. 81, 649-661

Larson L.L., Owen F.G., Albright J.L., 1977. Guidelines toward more uniformity in measuring and reporting calf experimental data. J. Dairy Sci. 60, 989-991

Mader T.L., Davis M.S., 2004. Effect of management strategies on reducing heat stress of feedlot cattle: Feed and water intake. J. Anim. Sci. 82, 3077-3087

Maltz E., Kroll O., Barash H., Shamy A., Silanikove N., 2000. Lactation and body weight of dairy cows: interrelationships among heat stress, calving season and milk yield. J. Anim. Feed Sci. 9, 33- 45

Mitlöhner F.M., Galyean M.L., McGlone J.J., 2002. Shade effects on performance, carcass traits, physiology, and behavior of heat-stressed feedlot heifers. J. Anim. Sci. 80, 2043-2050

Nienaber J.A., Hahn G.L., Eigenberg R.A., 1999. Quantifing livestock responses for heat stress management: a review. Int. J. Biometeorol. 42, 183-188

Niwińska B., Strzetelski J.A., 2004. Effects of type of liquid feed and feeding frequency on calf performance. J. Anim. Feed Sci. 13, Suppl. 1, 167- 170

Robertshaw D., 2006. Mechanisms for the control of respiratory evaporative heat loss in panting animals. J. Appl. Physiol. 101, 664-668

Soch M., 2005. Effect of Environment on Selected Indices of Cattle Welfare. University of South Bohemia, Česke Budejovice (Czech Republic), pp. 288

Soch M., Novak P., Kratochvil P., Travnicek J., 1999. Losses of water vapour in the relation to the stable climate factors in calves. Acta Hortic. Regiotecturae, Nitra (Slovakia) 2, 179-181

Spain J.N., Spiers D.E., 1996. Effects of supplemental shade on thermoregulatory response of calves to heat challenge in a hutch environment. J. Dairy Sci. 79, 639-646

Strzetelski J., Niwińska B., Kowalczyk J., Jurkiewicz A., 2001. Effect of milk replacer feeding frequency and level on concentrate intake and rearing performance of calves. J. Anim. Feed Sci. 10, 413- 420

West J.W., 2003. Effects of heat-stress on production in dairy cattle. J. Dairy Sci. 86, 2131-2144 